\title{
Improving the Educational Practice and Placement Opportunities for Hearing Impaired Students in Computer Science Engineering
}

\author{
Dr.D. Vanitha1, D.M. Rajan ${ }^{2}$ \\ ${ }^{1}$ Assistant professor, Centre for Speech and Hearing Impairment Programme, Kalasalingam Academy of Research and \\ Education, Krishnankoil, Tamilnadu, India \\ ${ }^{2}$ Special Educator, Kalasalingam Academy of Research and Education, Krishnankoil, Tamilnadu, India \\ 11.vanitha@klu.ac.in \\ ${ }^{2}$ m.rajan@klu.ac.in
}

\begin{abstract}
The present educational training methods present barrier for students with hearing impairment in Computer Science and Engineering (CSE) in accessing both information in the classroom as well as getting trained for placement. The suggested solution by many researchers recommending mixing of such students with normal students in doing classroom and project-related activities have reported leading to some psychological problem in the students with hearing impairment. The study proposes the use of support services such as interpreters, real-time captioning, assistive tools and note-making to enhance the effectiveness of the teaching-learning process. The effectiveness of the services must be evaluated by conducting frequent tests to know about the understanding level of the students and many mock interviews have to be conducted to get rid of their fear in facing the interviews. This can be done under the supervision of a sign language interpreter. At the Kalasalingam Academy of Research and Education, an attempt is made to implement this proposed step in collaboration with the industry who gives importance to the hearing impaired students. A survey conducted for the students, as well as the recruiters, involving about 300 students and 6 recruiters, indicate that such systematic training approach gives confidence to the students and their performance is found to be almost at par with the normal students, enabling such students to be effective engineers in the computing field who can confidently contribute their services to the society.
\end{abstract}

Keywords: Hearing impaired, Loop system, Auditory/Oral, KARE

\section{Introduction}

With the quick advances made in the field of instructive innovation, it is sensible to anticipate that physical handicaps, for example, hearing impairment are no longer hindrances to obtain advanced education. In any case, hard of hearing and hearing- impairment students may confront numerous impediments during the learning cycle because of their inabilities; they may encounter separation, low confidence, and learning difficulties [1]. Over $80 \%$ of hard of hearing individuals need instruction or are unschooled because they are not given the vital supporting learning facilities.

Hearing impairment ought not to be seen as hindrances to academic achievement, particularly with the fast advances in instructive innovation. Even though the quantity of hard of hearing students who are going to colleges and universities has expanded of late, a few investigations have demonstrated that most hard of hearing understudies don't complete their higher studies on account of a few challenges [2].

These problems range from the inability to hear either mostly or entirely, to the absence of special facilities to support them in overwhelming the personal and social barriers they meet due to hearing deficiency or loss or at least permit them to develop their learning proficiency as fast as their peers [3]. Subsequently, viable technological support is fundamental to improve the learning climate of hard of hearing- and hearing-impaired students.

\section{Background}

In most developing countries, one of the main challenges preventing hard-of-hearing and deaf students from getting the higher education that will equip them to support themselves economically is the absence of accurate and reliable data on the size, kinds, and causes of deafness in the region. This shows that the quantity of hard of hearing and deaf people getting to higher education remains very low. Scientific research on the most ideal approaches to instructing hard of hearing through virtual learning is basic towards expanding the education level. This investigation means to test the capacity of hard of hearing students contemplate and comprehend an exceptionally specialized subject, for example, computer programming and challenge the broad recognition that the hard of hearing can't learn complex subjects [4,5]. Kalasalingam Academy of Research and Education (KARE) is the first institution in India to offer the special B.Tech. Program for the Persons Hearing Impairment. This course was inaugurated by the former President of India Honourable Dr.A.P.J. Abdul Kalam on 05 Jan. 2007. This course is aimed at those people who need special attention and allow them to adapt themselves to the real-time challenges in the Engineering field. The Institute also has Speech and Audiology lab to monitor and enhance the speech and hearing levels of these students. The University has framed the curriculum and syllabus in such a way that after the completion of this course, these students 
will be on par with other Engineering graduates to cater to the needs of industries.

\section{Related Work}

This paper speaks about the work on hurdles and ways to deliver the contents to the students with hearing loss in computer science engineering designing instruction. Nonetheless, various past papers talk about Deaf/Hard of Hearing training in processing. Ross [6] portrayed a few strategies for instructing programming to hard of hearing students, one of which was with proficient notetakers and translators because of their absence brings about a critical loss of data.

Cavender et al.[7] depicted that all Deaf/ Hard of Hearing students have not followed similar communication through signing. Burgstahler et al. [8] examined a few different ways to equip their skills of hearing-impaired students in the field of computer science engineering with help of instructors and hearing students. Kheir and Way [9] examined the utilization of real-time speech transcription to help the Deaf/ hearing in software engineering courses. Bueno et al. [10] depicted a few techniques for helping teachers in adjusting e-learning content.

Notwithstanding the high number of studies highlighted making potential courses of action as advanced education helps for hearing impaired students and the affirmation of the shortage getting advanced education, simply a foreordained number of these strategies have been become up until now, especially for demonstrating certain astounding subjects, for instance, Computer Science and Programming $[11,12]$.

\section{Hearing Impaired Student in the University Context}

A university context is challenging for all young people. Issues of acclimating to academic life and the commitments, it forces regularly lead to disappointment and relinquishment. To absorb new data and information, they need to defeat the weaknesses of their past school insight, for example, language insufficiencies, deficient examination conditions, an absence of rationale aptitudes, issues with understanding appreciation and trouble in creating text [13]. Be that as it may, coordination requires not just the capacity to complete academic activities, yet additionally inclusion with associates, educators and the setting. Both are crucial in the early long stretches of advanced education for extemporizing chances of success [14]. Young hard of hearing individuals, similar to any others, must deal with desires, guidelines and ways of working that are not quite the same as their past school insight. Adjusting to this new reality will rely upon their qualities and abilities, their set of experiences and how they face up to this time of self-advancement as young adults, which is set apart by the development of character, selfgovernance, standards and relational connections. As mentioned in Foster et al,On the experience of hard of hearing students in advanced education in settings of inclusion shows that the view they have of correspondence in the classroom and their inclusion in the learning cycle is equivalent to that of their hearing associates, however, they feel less incorporated than the last into college life [15]. According to Goffredo, to meet the extraordinary instructive needs of youthful hard of hearing individuals, the initial step is to guarantee their entrance into the college through the selection test. In Kalasalingam Academy of Research and Education, the hearing-impaired students are admitted in the B.Tech. program based on their marks scored in the Higher secondary and the entrance exam conducted by the University.

\section{Selection of Course}

Computer science engineering is an easily accessible discipline for the hearing impaired students compared to the other one.[16]. At Kalasalingam Academy of Research and education, hearing impaired students are admitted for Computer science engineering department under the Centre for Speech and Hearing impairment Program (SHIP). Hearing-impaired students are dealt with simply like some other students in the program. we have accomplished a lot of progress in teaching students with hearing impairment in our Computer science engineering. we have additionally confronted critical obstacles. Notwithstanding the best endeavours of the translation of the sign language interpreter, hearing impaired students are inclined to lose a lot of both verbal and nonverbal correspondence through a mediator.

In this paper, we present a portion of our experiences and future work in making the strongest instructive experience as feasible for our hearing-impaired students in the Computer science educational process.

\section{Classroom Lectures}

As Martins (2006) points out, sign language interpretation ought to be fit for seeing the challenges of hearing-impaired students and of finding ways and techniques for moderating them. Cultivate, Long, and Snell (1999) raise different issues looked at by hearing-impaired students. The Methodology used in our University to teach the hearing-impaired students are Total Communication which includes auditory and visual communication for instruction. Active learning is achieved by Peer to Peer instruction, group discussion and collaborative problem-solving. every information is delivered by the use of Assistive Technology devices such as loop induction system which amplify sound from an instructor's microphone.

\section{A. Auditory/Oral}

When teaching hearing-impaired students, instructors ought to guarantee that the hearing and listening environment in the study hall is ideal for the kid. There ought to likewise be a negligible separation between the instructor and the student, so lip reading is simpler and the educator should confront the student during all oral correspondence. Educators ought to guarantee that there is acceptable lighting. 
Educators ought not to misrepresent elocution since this will deflect understanding. Teachers ought to now and again check to guarantee the listening gadgets are working appropriately.

There are several instructional aids are available in all classrooms to teach the hearing-impaired students. A teacher has more options while teaching such as a sign, fingerspelling and speech reading. Equipment, including overhead projectors, bulletin boards, computers and televisions showing captions on the screen, can also be used in teaching.

Instructors should remember that normally more than one visual thing is occurring at one time, such as an educator talking while at the same time anticipating that students should take notes of the talk. It isn't practical, notwithstanding, to expect a hearing-impaired student to understand lips while likewise taking notes. So, a copy of lecture notes/OHPs/PowerPoint slide has given to the students in advance. Lip-reading is easier when the subject area is known and also the students can acquaint with session content and vocabulary to be used.

Teachers are additionally encouraged to regularly check the hearing-impaired students to ensure the understanding of concepts in the class. At the point when the student doesn't comprehend what is being stated, the educator can reword with extra words pertinent to what the person needs to state.

\section{B. Loop systems}

Loop systems work by reducing background noise. Using the assistive listening devices such as induction loops which is available in the lecture rooms, the teaching methodology for the hearing-impaired students can be improved. Hearing aids may include transmitter/receiver systems with a clip-on microphone for the lecturer. A microphone gets sound from an individual talking (or a radio or TV) and feeds it to a wire loop going around a room. The student will at that point switch their amplifier or cochlear implant to the 'T setting' so it gets sound from the loop. The use of a microphone can make the lecture session, a casual one. There is no need to change the speaking or teaching style.

\section{Guidance and Counselling}

\section{A. Periodical Counselling}

The periodic counselling process is done by the faculty advisory system. In this system, a certain number of students are assigned to a faculty advisor to help the students in planning their courses of study and for getting general advice on the academic programme. The Faculty Advisor will help the students in all their endeavours during their period of study. After the first End-Semester examination, if the Faculty Advisor finds that any of his/her wards are showing poor performance for whatever reason(s), he/she will bestow special care and attention on him/her as per the Standard Practice Record (SPR) of the University.

B. Meet with parents regularly
While Kalasalingam Academy of Research and education has a large and excellent group of faculties who are acting as effective faculty advisors. They are readily and freely available to students upon request. Having an open line of correspondence with the student's parents will help us to ensure the consistent support given by the faculty members both at college and home. At that time of meeting with the parents, problems faced by the students in academic and non-academic are discussed. This is very helpful for us to track the student's progress.

\section{Our Experiences}

The main idea of this program is to provide effective teaching and learning which includes curriculum, instruction, assessment, classroom organization, and management. In both academia and industry, the students are probably going to work with hearing. The students need to figure out how to viably and effectively work with a different arrangement of individuals. In the campus, the hearing-impaired students have an opportunity to mix with hearing students in the nonacademic areas like hostels, auditorium, sports ground.

To comprehend the viewpoints of faculty and hearingimpaired students, we requested that each gathering round out an unknown review dependent on their experiences. The students vacillated from freshmen to seniors, and the vast majority of them had significant hearing loss [17].

In the following section, we will discuss some of the student feedback we received.

\section{A. Student Feedback}

We previously got some information about a portion of the greatest education challenges in their courses. A few reactions were:

"It's hard for all of us to understand the courses which are having only theory"

"The biggest challenge I had during class was trying to figure out the instructions given to me by the professor."

The hearing-impaired students gave blended surveys concerning their computer science engineering designing encounters. While a few students gave extremely positive experiences, others communicated concerns and disappointment over their encounters.

Numerous students additionally said that they wanted to utilize the short notes given by the faculties, as it helped them especially with looking into the course material after the lecture or lab hours.

"Short notes helped a large amount! It was very nice and convenient to be able to go back and look at the material on my own time."

"I used to see the video capturing of missed lectures to review them to increase the understanding of the particular subject. Since I started doing that, I feel like I'm more able to contribute to the class or group."

Table 1. Example Questions: Hearing-Impaired

Students

\begin{tabular}{|l|l|}
\hline Question & \multicolumn{1}{|c|}{ Responses } \\
\hline $\begin{array}{l}\text { Throughout the class } \\
\text { hours, do you feel that }\end{array}$ & $\begin{array}{l}\text { Yes: } 80 \%, \text { Sometimes: } \\
13 \%, \text { No: } 7 \%\end{array}$ \\
\hline
\end{tabular}




\begin{tabular}{|c|c|}
\hline $\begin{array}{l}\text { you are" in the loop" } \\
\text { about the coursework? }\end{array}$ & \\
\hline $\begin{array}{l}\text { During class time, do you } \\
\text { feel that you can follow } \\
\text { the instructions given by } \\
\text { the faculty members? }\end{array}$ & $\begin{array}{l}\text { Yes: } 70 \% \text {, Sometimes: } \\
13 \% \text {, No: } 17 \%\end{array}$ \\
\hline $\begin{array}{l}\text { Have the instructor used } \\
\text { any resources offered } \\
\text { for the support of hearing- } \\
\text { impaired students? }\end{array}$ & $\begin{array}{l}\text { Yes: } 90 \% \text {, Sometimes: } \\
5 \% \text {, No: } 5 \%\end{array}$ \\
\hline $\begin{array}{l}\text { How was your overall } \\
\text { experience with the other } \\
\text { members in the } \\
\text { University? }\end{array}$ & $\begin{array}{l}\text { Poor: } 3 \% \text {, Neutral: } 17 \% \text {, } \\
\text { Good: } 80 \%\end{array}$ \\
\hline $\begin{array}{l}\text { When working in a } \\
\text { gathering, do you feel } \\
\text { sure speaking with } \\
\text { hearing colleagues? }\end{array}$ & $\begin{array}{l}\text { Always: } 40 \% \text {, Sometimes: } \\
\text { 53\%, Rarely: } 7 \%\end{array}$ \\
\hline
\end{tabular}

\section{Jobs for the Hearing-Impaired students}

Employment is a significant factor in everybody's life. A decent acceptable occupation at the correct age makes the individual independent. The hearing-impaired students have an equivalent right to Employment fitting their capacity. Computers and other soft skills are perfectly suited for jobs for the deaf. People with technical skills can work as factory workers. This statement by Dr King Jordan sums up everything. "Deaf People Can Do Anything Hearing People Can - Except Hear".

\section{A. Placement training}

By collaborating with companies who are willing to place the hearing-impaired students, placement training is given regularly. The training services include

Communication skill training

Soft skill training

Programming language training

\section{Communication skill training}

Writing is a difficult assignment for all students, as communicating contemplations in words requires the exact spelling of words, the right utilization of language structure, semantic and businesslike aptitudes, and the precise utilization of accentuation. Composing articulation, which requires the joined utilization of different aptitudes, is a considerably additionally testing and complex errand for hearing-impaired students, who experience a deferral in the improvement of their language abilities [18]. In different investigations, hearing-impaired students are found to perform ineffectively in writing skills. To improve the writing skills, the training is given such as pre-writingrelated vocabulary before writing, composing, revising, editing, increasing the writing practice

\section{Soft skill training}

The training proposes the activities to improve linguistic intelligence, numerical skills, thinking skills. The basic knowledge about the recruitment process is clearly explained by the collaborating company. Mock interview sessions and group discussion are conducted to get rid of the fear to face the interviews

\section{Programming language training}

An initial analysis of deaf and hard hearing learners was undertaken to identify their basic learning requirements. This analysis includes measuring their willingness and readiness to study computer programming in addition to their ability to cognitively understand applied and practical problem-solving subjects. On the other hand, learning software in line with the help of companies requires a proper analysis for evaluating their usability. Simple animation and images were displayed on the board to support the illustration of the lesson.

\section{Future Work}

We surveyed a comparatively large number of hearingimpaired students and faculty. The survey explicates that the use of technology and computing to support hearingimpaired students in academic activities will not replace the need for skilled interpreters. The interpreters only transmit the information clearly and effectively to the hearingimpaired students. For our students, we select to use interpreters over technologically-based communication. This will increase the understanding level of the students. So, it is proposed to modify the curriculum according to the needs of the recruiters.

\section{Conclusion}

Hearing-impaired students are typically understated and encounter noteworthy sprints in the curriculum of computing in higher education. We are offering B.Tech course on computer Science engineering. While there are numerous challenges yet to be overcome, students with hearing impairment got benefited from our work and they are placed in reputed companies. From that work, we understood that no technology replaces the sign language which is the mother tongue of Hearing-Impaired students. But, the students those who fully depend on sign language can't perform well in the placement activities. Additionally, we encourage further research and knowledge sharing to improve Hearing-impaired students' education.

\section{Acknowledgement}

Authors thanks the Vice-chancellor and Management of Kalasalingam Academy of Research and Education for their support and encouragement to carry out the research

\section{References}

[1] Van Gent, T., et al., (2012) Self-concept and ego development in deaf adolescents: a comparative study. Journal of deaf studies and deaf education, 17(3),333-351.

[2] Andrei, S., L. Osborne, and Z. Smith, (2013) Designing an American Sign Language Avatar for 
Learning Computer Science Concepts for Deaf or Hard-of-Hearing Students and Deaf Interpreters. Journal of Educational Multimedia and Hypermedia, 22(3), 229-242

[3] Esam, Nihal, Abbas, Areej and Krause, Paul (2017) Towards Empowering Hearing-Impaired Students' Skills in Computing and Technology International Journal of Advanced Computer Science and Applications, 8 (1).

[4] Goldin-Meadow, S., (2005) The resilience of language: What gesture creation in deaf children can tell us about how all children learn language. Psychology Press

[5] Bisol, C.A., et al., (2010) Deaf students in higher education: reflections on inclusion. Cadernos de Pesquisa, 40(139), 147-172

[6] R. J. Ross. (1982) Teaching programming to the deaf. SIGCAPH Comput. Phys. Handicap., (30), 18-26

[7] A.C. Cavender, R. E. Ladner, and R. I. Roth. (2009) The summer academy for advancing deaf and hard of hearing in computing. In Proceedings of the 40th ACM technical symposium on Computer science education, SIGCSE '09, 514-518, New York, NY, USA, ACM.

[8] S. Burgstahler, R. Ladner, and D. Comden. (2007) Broadening participation of people with disabilities in computing fields. In Frontiers In Education Conference - Global Engineering: Knowledge Without Borders, Opportunities Without Passports, FIE '07. 37th Annual, T3A-12-T3A-15,

[9] R. Kheir and T. Way. (2007) Inclusion of deaf students in computer science classes using realtime speech transcription. SIGCSE Bull., 39(3),261- 265.

[10] F. J. Bueno, M. G. Alonso, and J. R. F. del Castillo. (2007) Assisting lecturers to adapt e-learning content for deaf students. In Proceedings of the 12th annual SIGCSE conference on Innovation and technology in computer science education, ITiCSE '07, 335-335, New York, NY, USA, ACM.

[11] E. Krutz, S. A. Malachowsky, S. D. Jones and J. A. Kaplan (2015) Enhancing the educational experience for deaf and hard of hearing students in software engineering," 2015 IEEE Frontiers in Education Conference (FIE), El Paso, TX, 1-9.

[12] Harry G. Lang (2002) Higher Education for Deaf Students: Research Priorities in the New Millennium, The Journal of Deaf Studies and Deaf Education, 7 (4) 267-280,

[13] Sampaio, I. S.; Santos, A. A (2002) Reading and writing in university students: the assessment of an intervention program Psicologia em Estudo, Maringá 7(1) 31-38.

[14]Diniz, A. M.; Almeida, L. S. (2005) The scale of social integration in higher education: construction and validation methodology] Análise Psicológica, $4(23) 461-476$.
[15] S Foster, G Long, K Snell, (1999) Inclusive instruction and learning for deaf students in postsecondary education., The Journal of Deaf Studies and Deaf Education, 4(3) 225-235

[16] Andrei, S., L. Osborne, and Z. Smith (2013) Designing an American Sign Language Avatar for Learning Computer Science Concepts for Deaf or Hard-of-Hearing Students and Deaf Interpreters. Journal of Educational Multimedia and Hypermedia, 22(3): p. 229-242.

[17] Siegel, L. (2000). The educational and communication needs of deaf and hard of hearing children: A statement of principle on fundamental educational change. American Annals of the Deaf, 145(2), 63-78.

[18] Schirmer, B. R. (2000). Language and literacy development in children who are deaf (2nd ed.). Boston: Allyn and Bacon, Inc.

\section{Corresponding Author}

Dr. D. Vanitha, Assistant professor, Centre for Speech and Hearing Impairment Programme, Kalasalingam Academy of Research and Education, Krishnankoil, Tamilnadu, India, email: d.vanitha@klu.ac.in 